\title{
Perancangan Sistem Informasi Manajemen Kas Berbasis Web Studi Kasus: RS dr. Etty Asharto Batu
}

\author{
Supriyono, Endah Muslimah
}

\begin{abstract}
Pengelolaan data keuangan perusahaan merupakan hal yang perlu mendapatkan penanganan yang tertib, terstruktur dan transparan. Penerapan sistem informasi manajemen keuangan dapat dijangkau melalui situs lokal yang memberikan rincian data penerimaan kas dan pengeluaran kas. Metodologi yang digunakan didalam penelitian berikut menggunakan metode waterfall. Hasil dari penelitian berikut ini berupa sebuah perancangan sistem informasi yang mampu mengelola pemasukan kas dan pengeluaran kas. Sistem informasi pengelolan kas masuk dan kas keluar dirancang menggunakan database MySQL, bahasa pemrograman PHP, dengan tampilan user interface menggunakan Bootstrap dan kerangka kerja menggunakan framework Codeigniter. Dengan menggunakan analisa dan perancangan sistem serta rekayasa kebutuhan dapat menghasilkan sistem informasi yang handal dan tepat guna. Sistem informasi pengelolaan kas masuk dan kas keluar pada Rumah Sakit dr. Etty Asharto Batu mampu memberikan manfaat bagi pegawai dalam proses pencatatan.
\end{abstract}

Index Terms - Sistem Informasi Manajemen, waterfall, codeigniter, arus kas.

\section{PENDAHULUAN}

Aktivitas pencatatan kas yang baik adalah pencatatan kas yang rinci mengenai kondisi keuangan. Hal tersebut tidak akan didapatkan manakala menggunakan cara $A$. manual. Kemampuan untuk penyedia laporan keuangan secara detil juga harus ditunjang dalam pengelola yang diperlukan oleh bagian dan pihak manajemen dan keuangan.

Pada Rumah Sakit dr. Etty Asharto Batu yang tergolong instansi dengan skala menengah keatas masih menggunakan cara yang konvensional untuk melakukan pengelolaan transaksi keuangan. Bagian bendahara dan kasir merasa kesulitan ketika harus membuat laporan keuangan atau arus kas. Kelemahan pengelolaan laporan akuntansi di Rumah Sakit dr. Etty Asharto Batu yang

Manuscript received July 24, 2007. This work was supported in part by Informatics Engineering Department of Maulana Malik Ibrahim Islamic State University.

Supriyono Author is with the Informatic Engineering Departement of Maulana Malik Ibrahim Islamic State University , Malang, Indonesia; (email priyono@ti.uin-malang.ac.id)

Endah Muslimah was with the Vocational education program, Brawijaya University, Malang, Indonesia (e-mail: muslimah.endah@gmail.com). masih menggunakan cara manual diantaranya adalah belum ada integrasi data transaksi sistem informasi manajemen rumah sakit dengan manajemen kas masuk dan kas keluar serta laporan yang disajikan saat ini masih menggunakan bantuan perangkat lunak Microsoft Excel dengan cara menginputkan satu persatu sehingga rawan terjadi kesalahan dan membutuhkan waktu yang lama. Dari hasil identifikasi permasalahan yang ditemukan diperlukan sebuah sistem informasi manajemen kas berbasis web dengan tujuan mempercepat proses penyajian laporan secara realtime dan membutuhkan waktu yang singkat. Sistem yang dikembangkan berbasis web dengan harapan dapat memudahkan integrasi sistem informasi sebelumnya dan memudahkan proses pemeliharaan sistem karena cukup mengupdate source code pada server maka secara otomatis semua user dapat menggunakan aplikasi yang dikembangkan.

Berdasarkan latar belakang yang telah diuraikan, penelitian berikut ini membahas terkait dengan bagaimana cara membangun sistem informasi pengelolaan kas masuk dan kas keluar yang efektif dan efisien. Sistem informasi dikembangkan dengan berbasis web menggunakan bahasa pemrograman PHP dan Framework Codeigniter.

\section{TINJAUAN PUSTAKA}

\section{Arus Kas}

Kas merupakan alat pertukaran yang yang dimiliki perusahaan dan siap digunakan dalam transaksi perusahaan. Dalam laporan posisi keuangan kas merupakan aset yang paling lancar. Laporan arus kas adalah salah satu dari laporan keungan dasar. Laporan ini berguna bagi manajer dalam mengevaluasi operasi masa lalu dan merencanakan aktivitas investasi serta pendanaan di masa depan. Laporan ini juga berguna bagi para investor, kreditor, dan pihak-pihak lainnya menyediakan dasar untuk menilai kemampuan perusahaan membayar utangnya yang jatuh tempo.

\section{B. Framework Codeigniter (CI)}

Codeigniter merupakan framework pengembangan program aplikasi dengan menggunakan bahasa pemrograman PHP. Framework CI merupakan suatu kerangka untuk bekerja atau membuat program dengan menggunakan PHP yang lebih sistematis. Pemrogram tidak perlu membuat program dari awal karena CI menyediakan sekumpulan library yang banyak yang 
diperlukan untuk menyelesaikan pekerjaan yang umum, dengan menggunakan antarmuka dan struktur logika yang sederhana untuk mengakses librarinya. Pemrogram dapat memfokuskan diri pada kode yang harus dibuat untuk menyelesaikan suatu pekerjaan.

CI merupakan framework yang memiliki lisensi bebas untuk digunakan, karena menggunakan lisesnsi open-source Apache atau BSD. CI dikembangkan pertama kali oleh Rick Ellis. Framewrok CI merupaka framework yang memiliki dokumentasi yang jelas dan lengkap, yang memudahkan pengembang untuk mempelajari dengan mudah. Pendekatan dari CI sangatlah mudah, dari membuat sekadar tulisan sampi dengan kompleks dapat didekati dengan mudah.

Penelitian terkait mengenai perancangan sistem informasi pelaporan keuangan berbasis web studi kasus pada PT.EMKL Tirtasari Abadi Sejahtera Semarang dengan menggunakan pendekatan metode System Development Life Cycle(SDLC) dengan tujuan menghasilkan laporan keuangan secara cepat, efektif dan efisien. [7]. Pengolahan kas yang tidak tercatat dengan baik dapat menyebabkan penggunaan dana diluar dari perencanaan dan memungkinkan terjadi kerugian bagi perusahaan atau instansi. Teknik Object Oriented Software Engineering (OOSE) didalam mengembangkan aplikasi arus kas masuk dan keluar dengan obyek penelitian di Primer Koperasi Kartika Gajah Mada III dapat meghasilkan pelaporan keuangan secara periodik. [9]

\section{METODOLOGI PENELITIAN}

Dalam perancangan sistem informasi pada penelitian berikut ini dilakukan dengan pendekatan Data Flow Diagram $(D F D)$. Pendekatan perancangan sistem informasi dengan DFD merupakan alat perancangan sistem yang berorientasi pada alur data dengan konsep dekomposisi yang dapat digunakan untuk penggambaran analisa maupun perancangan sistem yang mudah dikomunikasikan oleh pengembang sistem kepada pengguna sistem.

Diagram konteks adalah diagram yang terdiri dari suatu proses dan menggambarkan ruang lingkup suatu sistem. Diagram konteks merupakan level tertinggi dari DFD yang menggambarkan seluruh input ke sistem atau output dari sistem. Ia akan memberi gambaran tentang keseluruhan sistem. Sistem dibatasi oleh boundary. Dalam diagram konteks hanya ada satu proses. Tidak boleh ada store dalam diagram konteks.

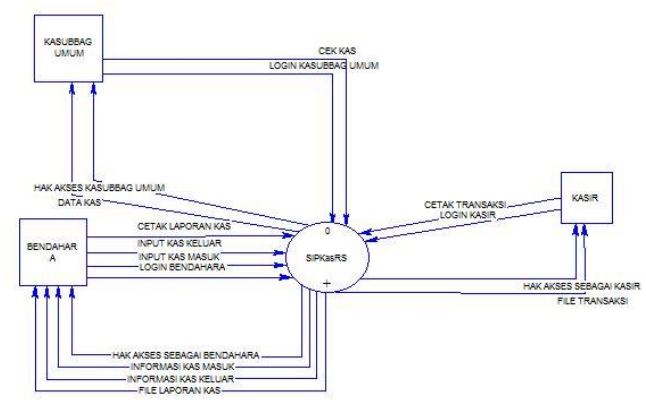

Gambar 1. Diagram Konteks

Diagram level 0 merupakan diagram yang menggambarkan proses dari dataflow diagram. Diagram nol memberikan pandangan secara menyeluruh mengenai sistem yang ditangani, menunjukkan tentang fungsi yang ditangani, menunjukkan tentang fungsifungsi utama atau proses yang ada, Aliran Data, dan Ekternal Entity. Diagram level nol merupakan pemecahan dari diagram konteks ke diagram Nol, di dalam diagram ini memuat penyimpanan data.

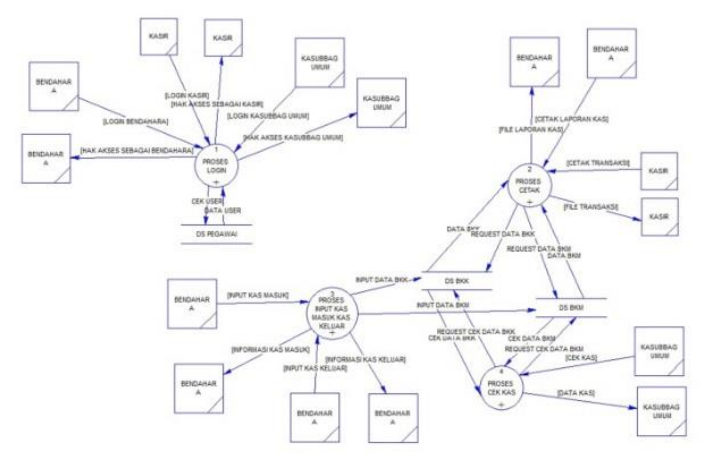

Gambar 2. Data Flow Diagram Level 0

Diagram DFD level 1 Proses Login, merupakan proses utama dari proses yang lain. Proses ini menjelaskan mengenai alur pengecekan hak akses untuk masuk kedalam aplikasi.

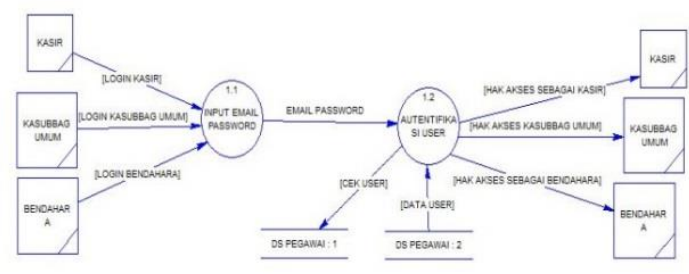

Gambar 3. Data Flow Diagram Level 1 Proses Login

Diagram DFD Level 1 Proses Input, merupakan proses kedua setelah Login. Diagram ini menjelaskan mengenai alur memasukkan data yang dapat dijelaskan pada gambar seperti berikut ini.

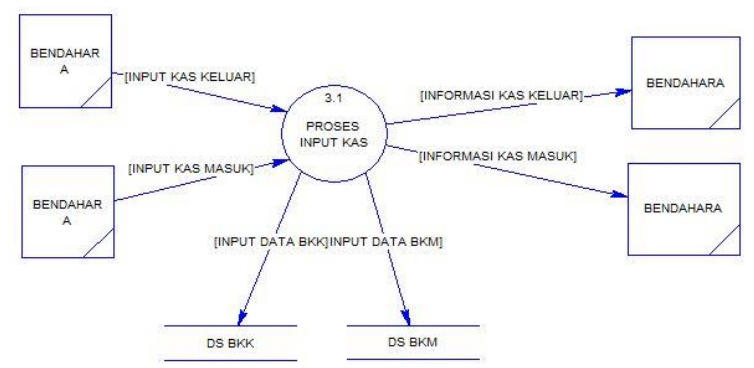

Gambar 4. Data Flow Diagram Level 1 Proses Input

Diagram DFD Level 1 Proses Cetak, merupakan proses ketiga. Diagram ini menjelaskan mengenai alur dari proses mencetak sebuah laporan transaksi yang dapat dijelaskan pada gambar seperti berikut ini. 


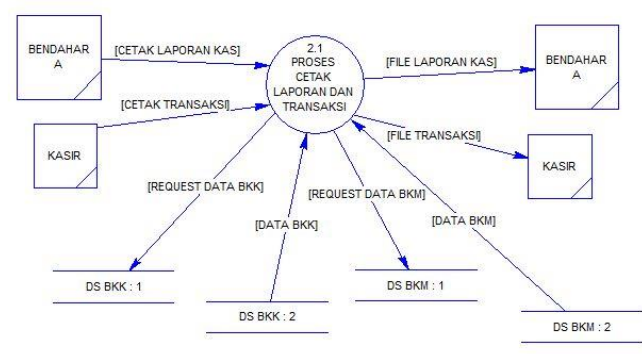

Gambar 5. Data Flow Diagram Level 1 Proses Cetak

Diagram DFD Level 1 Proses Cek, merupakan proses terakhir. Diagram ini menjelaskan mengenai alur Cek Transaksi sesuai dengan hak akses yang dapat dijelaskan pada gambar seperti berikut ini.

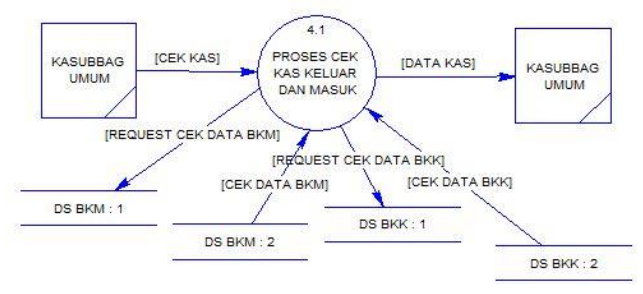

Gambar 6. Data Flow Diagram Level 1 Proses Cek

Perancangan basis data merupakan proses menciptakan perancangan untuk basis data yang akan mendukung operasi dan tujuan perusahaan. Relasi antar tabel dalam Perancangan Sistem Informasi dijelaskan pada gambar berikut ini.

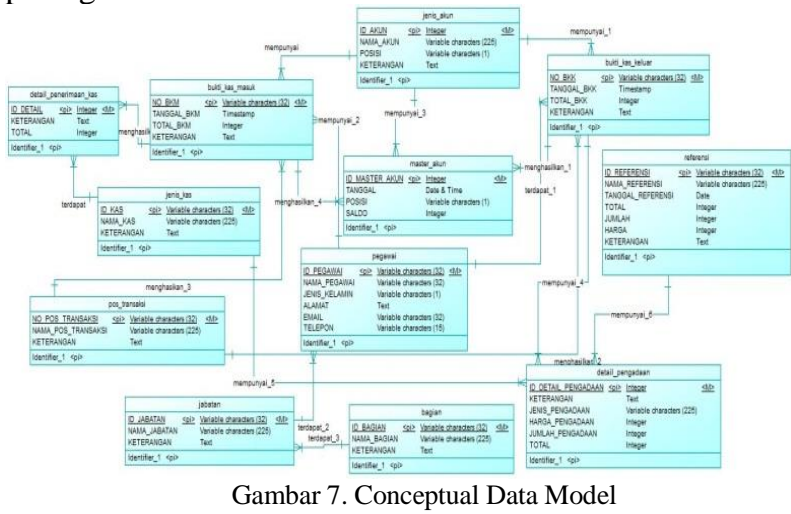

Entity Relational Diagram (Physical Data Model) pada Sistem Informasi Pengelolaan Kas Masuk dan Kas Keluar Rumah Sakit dr. Etty Asharto lebih lengkapnya akan dijelaskan pada gambar dibawah.

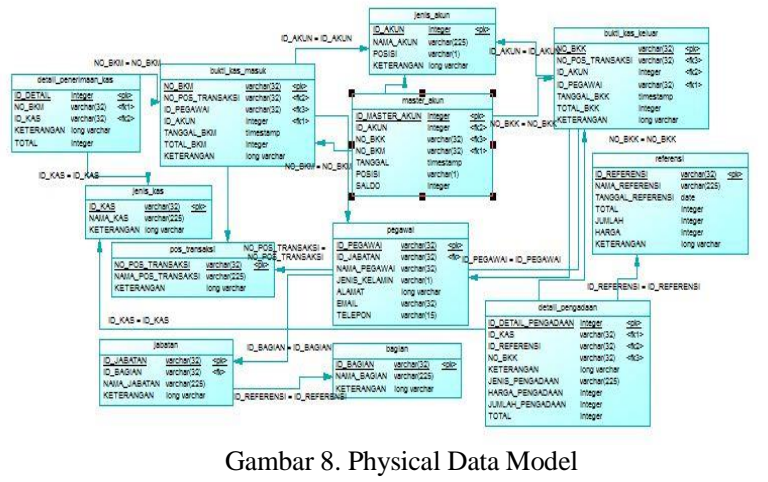

Data yang diperoleh untuk pengujian sistem informasi manajemen kas bersumber dari data manual yang disajikan oleh bagian akuntansi Rumah Sakir dr. Etty Asharto. Data yang digunakan meliputi data kas masuk dan data kas keluar berdasarkan periode tertentu. Teknik pengujian aplikasinya dengan menggunakan pendekatan pengujian aplikasi berdasarkan tingkat fungsional sistem informasi manajemen kas yang dikembangkan.

\section{HASIL}

Berikut adalah implementasi program mulai dari awal hingga akhir :

a. Tampilan Awal

Tampilan Login untuk Administrator (pegawai). Tampilan awal difungsikan untuk Administrator yang berhak untuk Login dengan memasukkan Email dan Password pada tempat yang telah disediakan. Admin yang telah sukses Login dapat terekam pada sistem. Setelah suskses untuk melakukan Login, Pihak Administrator (pegawai) mampu mencatat Penerimaan Kas Masuk.

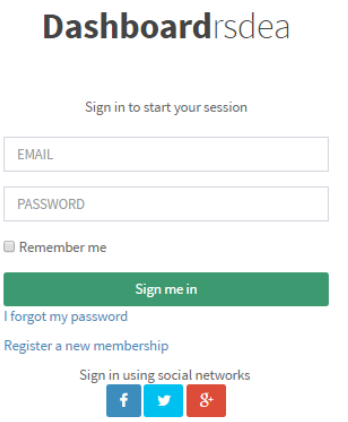

Gambar 9. Halaman Awal Login

\section{b. Menu Master}

Tampilan pada gambar dibawah merupakan Menu Master Data, yang terdiri dari beberapa menu, antara lain Tabel Bagian, Tabel Jenis Kas, Tabel Jenis Akun, Tabel Referensi, Tabel Pos Transaksi, Tabel Jabatan, dan Tabel Pegawai. Menu ini merupakan bagian dari atribut Tabel Pegawai.

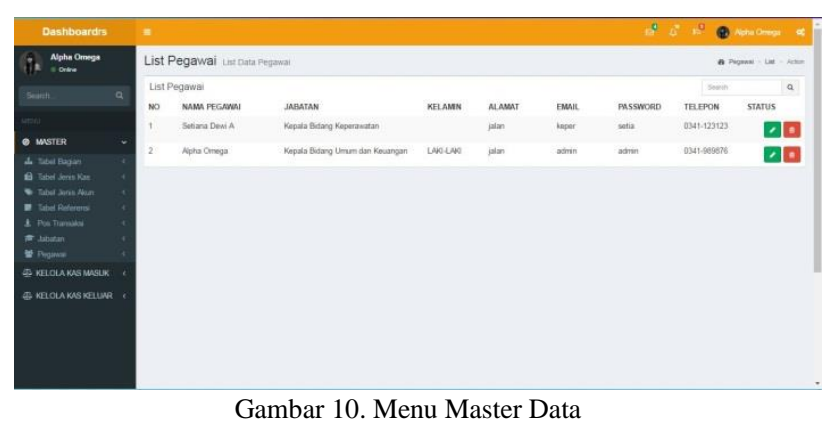

c. Menu Kelola Kas Masuk

Gambar dibawah merupakan gambar Menu List Bukti Kas Masuk (BKM) yang termasuk Menu Kelola Kas Masuk. Pada menu ini, menu transaksi penerimaan kas dapat terekam denga waktu realtime atau waktu sekarang. Pada menu ini, terdapat beberapa bagian yang tergolong bukti kas masuk antara lain ; Nama Pegawai, Nomor BKM, Jenis Akun, Pos Tramsaksi, Total BKM, Keterangan dan Action ata Status. Pada menu bukti kas 
masuk, terdapat beberapa menu action yaitu Creat, Update, Delete dan Detail.

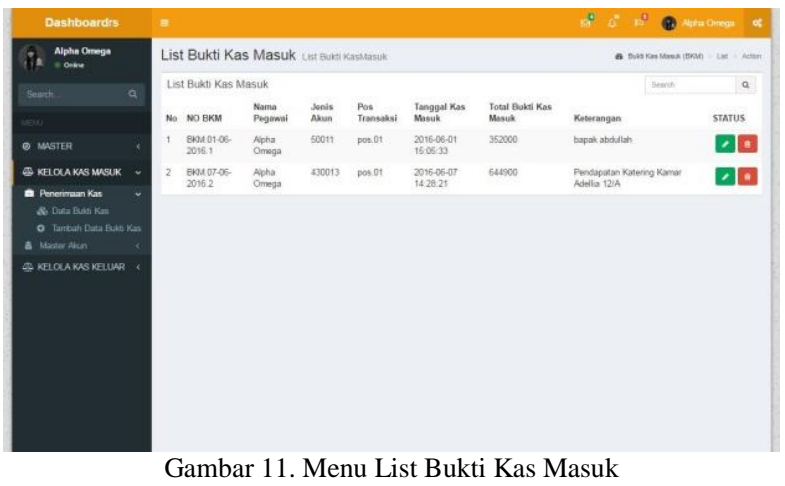

d. Menu Ke-dua Kelola Kas Masuk

Pada menu kedua kelola kas masuk merupakan bagian dari bukti kas masuk yang terdiri dari Detail Bukti Kas Masuk. Pada menu ini, dapat dilihat transaksi yang masuk atau bukti kas masuk dapat dijelaskan dengan detail.

Pada menu ini terdapat menu Export File berupa PDF dan Excel.

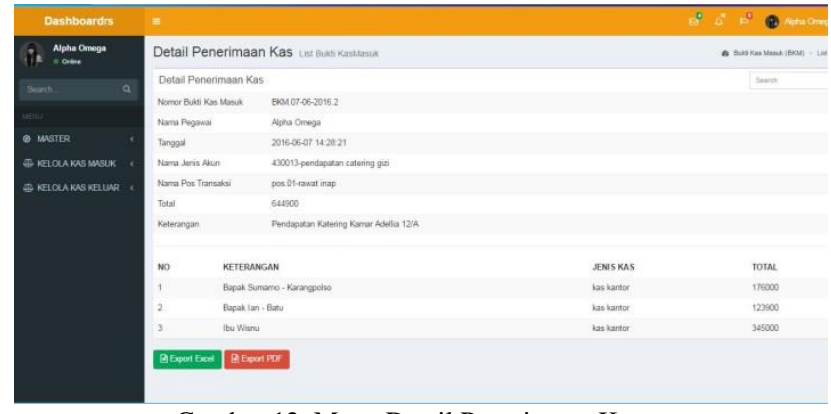

Gambar 12. Menu Detail Penerimaan Kas

\section{e. Menu Kelola Kas Keluar}

Gambar dibawah merupakan gambar menu List Bukti Kas Keluar, menu ini merupakan menu transakasi pengeluaran atau Bukti Kas Keluar (BKK). Pada menu ini, transaksi pengeluaran kas terekam dengan waktu real time atau waktu sekarang. Yang tergolong dalam Bukti Kas Keluar antara lain ; No BKK, ID Jenis Akun, No Pos Transaksi, Tanggal BKK, Keterangan dan Satatus. Pada menu Bukti Kas Keluar, terdapat beberpa menu Action Creat, Update, Delete dan Detail

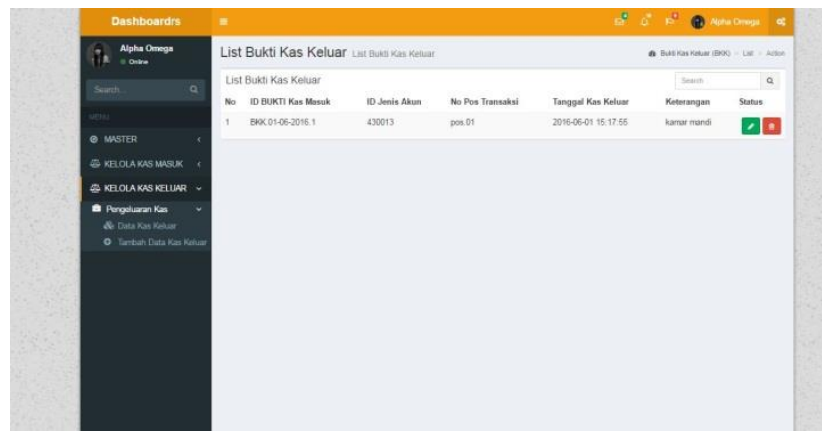

Gambar 13. Menu List Bukti Kas Keluar (BKK) f. Menu ke-dua Kelola Kas Keluar

Pada menu kedua kelola kas keluar merupakan bagian dari bukti kas keluar yang terdiri dari Detail Bukti Kas Keluar. Pada menu ini, dapat dilihat transaksi yang keluar atau bukti kas keluar dapat dijelaskan dengan detail.

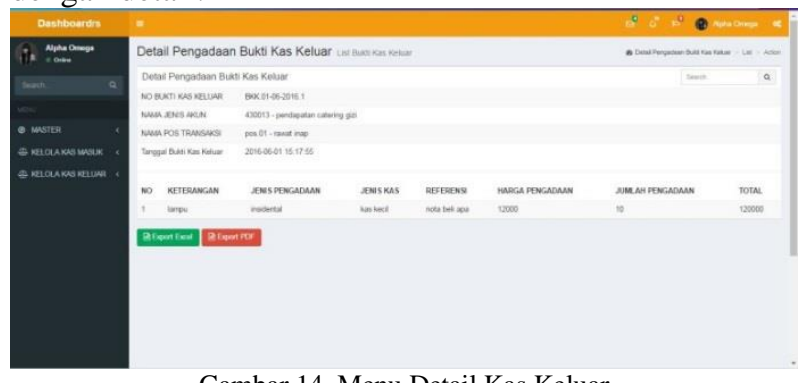

Gambar 14. Menu Detail Kas Keluar

g. Menu Ke-tiga Kelola Kas Masuk

Terdapat menu Master Akun pada menu Kelola Kas Masuk, menu Master Akun merupakan menu dari semua transakasi yang telah tercatat atau terekam. Menu Master Akun secara otomatis bisa bertambah dan berkurang ketika sebuha transaksi dilakukan. Pada menu ini juga terdapat detail dari sebuha transaksi yang telah dilakukan.

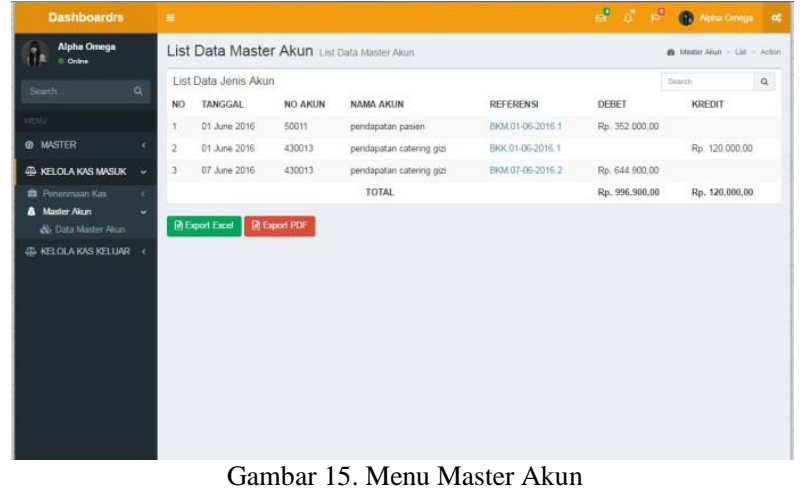

h. Menu Cetak Laporan atau BKM, dibawah merupakan tampilan dari hasil cetak laporan Bukti Kas Masuk.

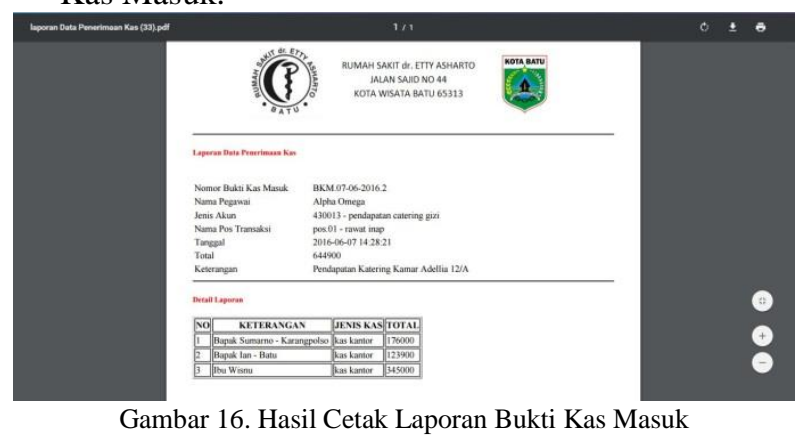

Menu Cetak Laporan Pengeluaran Kas atau BKK, dibawah merupakan tampilan dari hasil cetak laporan Bukti Kas Keluar. 


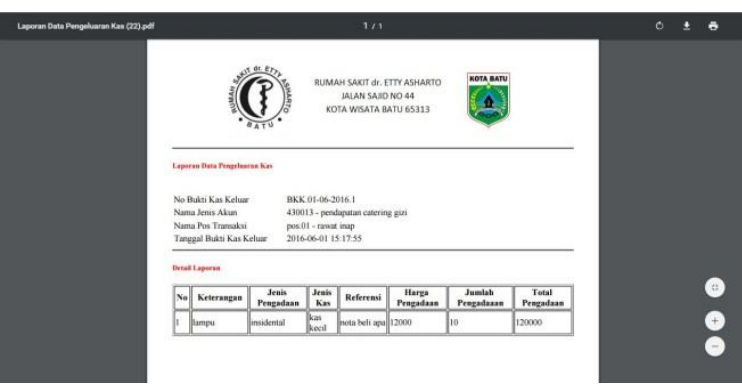

Gambar 14. Hasil Cetak Laporan Bukti Kas Keluar

Hasil akurasi pencatatan kas masuk dan kas keluar dapat diukur dari tingkat kecepatan dalam memproses pengelolaan kas yang sesuai dengan perencanaan dan alokasi dana kas

\section{KESIMPULAN DAN SARAN}

Berdasarkan penelitian berikut ini dapat menghasilkan sebuah kesimpulan diantaranya, perancangan Sistem Informasi Pengelolaan Kas Masuk dan Kas Keluar dirancang menggunakan perancangan Entity Relationship Diagram (ERD) dengan tabel entitas berjumlah 12. Sistem informasi pengelolaan kas dirancang dengan menghasilkan laporan keuangan secara real time sehingga mendukung pengguna sistem untuk bekerja lebih efektif dan efisien. Dengan adanya sistem informasi pengelolaan kas dapat mengurangi tingkat kesalahan manajemen kas yang tidak sesuai dengan perencanaan.

Berdasarkan penelitian yang dibahas terdapat beberapa keterbatasan dari sisi metodologi penelitian dan integrasi sistem yang berbeda platform pengembangan sistem informasi manajemen kas. Oleh Karen itu diperlukan adanya metodologi pembanding dan meningkatkan akurasi laporan keuangan yang dihasilkan dari sistem yang dikembangkan. Pengembangan sistem informasi yang lebih kompleks dan terintegrasi dengan Sistem Informasi Rumah Sakit dr. Etty Asharto dapat ditingkatkan lagi dengan menggunakan teknologi web services sehingga permasalahan teknik pengembangan program aplikasi yang berbeda platform dapat lebih akurat.

\section{DAFTAR PUSTAKA}

[1] Armando, D. (2013, September 21). Pengertian Basisdata menurut Para Ahli. Dipetik 04 02, 2016, dari http://doniarmando910.blogspot.co.id/2013/09/pengertian-basisdata-menurut-para-ahli.html

[2] Dr. Suarga, M. M. (2012). Algoritma dan Pemrograman. Yogyakarta: Andi.

[3] Eti Rochaety, F. R. (2017). Sistem Informasi Manajemen. Mitra Wacana edika

[4] Jusup, Al.haryono.(2011). Dasar-Dasar Akuntansi. STIE YKPN Yogyakarta

[5] Kroenke, D. M. (2011). Dasar - dasar, Desain, dan Impelementasi Database Processing. Jakarta: Erlangga.

[6] Ladjamudin, A. -B. (2005). Analisis dan Desain Sistem Informasi. Yogyakarta: Graha Ilmu.

[7] Mukhofifah, Umi. Migunani (2015). Perancangan Sistem Pelaporan Keuangan Berbasis Web (Studi Kasus Pada Pt.Emkl Tirtasari Abadi Sejahtera Semarang). Jurnal Teknologi Informasi dan Komunikasi, ISSN:2087-0868, Volume 6 Nomor 2 September

[8] Nugroho, A. (2015). Perancangan dan Implementasi Sistem Basis Data. Yogyakarta: Andi.

[9] Nuraela, Ela. Dkk. (2014). Aplikasi Kas Masuk dan Keluar di Primer Koperasi Kartika Gajah Mada III. Jurnal Computech dan Bisnis, Vol.8, No.2 Desember, 70-79 ISSN 2442-4943

[10] Pengertian dan penjelasan boostrap. (t.thn.). Dipetik 0504 , 2016, http://www.codeberkas.xyz/framework/bootstrap/pengertiandan-penjelasan-bootstrap/

[11] Pengertian Kas. (t.thn.). Dipetik 04 18, 2016, dari http://infodanpengertian.blogspot.co.id/2016/01/pengertian-kasmenurut-para-ahli.html

[12] Rudianto. (2012). Pengantar Akuntansi. Jakarta: Erlangga.

[13] Saputra, A. (2012). PHP.HTML dan CSS. Jassakom.

[14] Thomas Sumarsan, S. M. (2011). Akuntansi Dasar dan Aplikasi Dalam Bisnis. Jakarta: Indeks.

[15] Yuni Sugiarti, S. M. (2013). Analisis dan Perancangan UML (Undified Modeling Language) Generated VB.6. Yogyakarta: Graha Ilmu. 